\title{
Efeito do Estresse Térmico e do Exercício sobre Parâmetros Fisiológicos de Cavalos do Exército Brasileiro
}

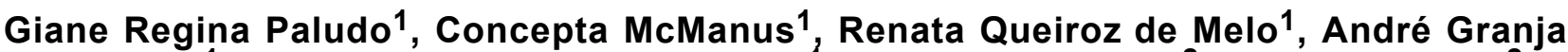 \\ Cardoso ${ }^{1}$, Fabíola Peixoto da Silva Mello ${ }^{1}$, Moryenne Moreira ${ }^{2}$, Beatriz H. Fuck ${ }^{2}$
}

\begin{abstract}
RESUMO - Os cavalos do exército brasileiro são usados em dias de exposição e, muitas vezes, submetidos a exercício intenso, que, aliado às condições climáticas do cerrado do Centro-Oeste brasileiro, resulta na necessidade de extrema aclimatação dos mesmos. O objetivo desse estudo foi determinar o efeito do estresse térmico e do exercício a que estão submetidas às raças de eqüinos estudadas. Foram utilizados 40 cavalos adultos (4 a 13 anos) do $1^{\circ}$ Regimento de Cavalaria de Guarda (10 animais de cada uma das raças Puro Sangue de Corrida - PSC, Mestiço - M e Brasileiro de Hipismo - BH) e do $32^{\circ}$ Grupo de Artilharia de Campanha (10 animais da raça Bretã), localizado no Setor Militar Urbano do Distrito Federal. Foram realizadas três medidas das freqüências cardíaca e respiratória, da temperatura retal e colhidas amostras de sangue quatro vezes por dia, de manhã e à tarde, antes e depois dos animais terem sido submetidos a exercício. A raça afetou todas as características exceto VCM, HCM e CHCM. Animais da raça PSC tiveram médias mais altas para leucócitos $(7,83 \pm 1,59)$, hemácias $(9,21 \pm 1,27), \mathrm{VG}(40,75 \pm 4,58)$ e hemoglobina $(14,34 \pm 1,67)$, enquanto os mestiços tiveram médias mais altas para proteína plasmática total $(6,93 \pm 0,66)$. Na raça Bretã foram observados níveis mais baixos para a maioria das características examinadas. O exercício afetou todas as características exceto VCM, HCM e CHCM com o nível das características aumentando em todos os casos. As correlações entre as características investigadas variam muito, sendo que entre hemácias, hemoglobina, VG foram em geral altas e positivas $(>0,58)$, enquanto com a proteína plasmática total foram de médias a baixas $(<0,26)$. O presente experimento nos permite concluir que os animais da raça PSC são os mais susceptíveis e os da raça Bretã os melhores adaptados às condições do clima do DF.
\end{abstract}

Palavras-chave: aclimatação, estresse, calor, respostas fisiológicas, exercício

\section{Effect of Heat Stress and Exercise on Physiological Parameters of Horses of the Brazilian Army}

ABSTRACT - The horses of the Brazilian army are used for expositions, and frequently subjected to intense exercise. This, together with environmental conditions of the Central west savanna result in the need for acclimatization. The objective of this study was to determine what is the effect of thermal and exercise stress on four groups of stabled horses in the savanna region. 40 Adult horses (4 to 13 years of age) from the $1^{\text {st }}$ Mounted Guard Regiment (10 of each breed Thoroughbred - PSC, Crossbred - M and Brazilian Showjumper $-\mathrm{BH})$ as well as 10 Bretãs from the $32^{\text {nd }}$ Campaign Artillery Group, were used. All horses were kept in the Urban Military Sector in the Federal District. The measurements made on the animals included heart and respiratory rates, rectal temperature and blood samples were taken at four opportunities during the day, in the morning and afternoon, before and after exercise. Genetic group influenced all traits except VCM, HCM e CHCM. Animals of the PSC group had higher means for leukocytes $(7.83 \pm 1.59)$, hematocytes $(9.21 \pm$ 1.27), VG (40.75 \pm 4.58$)$ and hemoglobin $(14.34 \pm 1.67)$, while crossbreds had higher total plasmatic protein levels $(6,93 \pm 0,66)$. The Breton breed had lowest levels for the majority traits examined. Exercise increased all traits except VCM, HCM and CHCM. The correlations between traits vary greatly, the highest being between hematocytes, hemoglobin and VG $(>0.58)$, while with total plasma protein they were low $(<0.26)$. The present work allows us to conclude that in terms of exercise of horses of the Brazilian army PSC are worst adapted and Bretã best adapted to the conditions of this study.

Key Words: acclimatization, heat stress, physiological responses

\section{Introdução}

Os cavalos do Exército Brasileiro são utilizados nos quartéis em tarefas diárias além de participarem de desfiles e de missões em que o Exército está envolvido. Nessas atividades os animais são submeti- dos a exercícios físicos intensos aliado ao clima seco e quente do Distrito Federal, sendo necessária grande aclimatação. As variações climáticas são fatores estressantes para os animais que devem ser capazes de induzir respostas fisiológicas, a fim de suportar melhoram as condições ambientais adversas. 
Para os cavalos, entre os fatores mais estressantes, podem-se citar o transporte, o exercício, a laminite, além de mudanças na temperatura e umidade ambiente (Foreman \& Ferlazzo, 1996). Segundo Barbosa \& Silva (1995), os quatro elementos ambientais que mais afetam a temperatura corporal são: temperatura do ar, umidade do ar, radiação e vento. A exata combinação desses elementos na qual se inicia o estresse calórico é difícil se não impossível de se especificar, uma vez que dada combinação pode ser favorável ou desfavorável, dependendo do animal e das condições particulares na qual ele se encontra. No Distrito Federal observamos mudanças significativas na temperatura e umidade durante as estações do ano, duas estações bem definidas caracterizadas por altas temperaturas tanto com baixa quanto com alta umidade. A adaptabilidade pode ser avaliada pela habilidade do animal de se ajustar às condições ambientais médias, assim como aos extremos climáticos (Baccari Jr., 1986). Animais bem adaptados caracterizam-se pela manutenção ou mínima perda no desempenho produtivo durante o estresse, alta eficiência reprodutiva, alta resistência às doenças, longevidade e baixa taxa de mortalidade (Barret \& Larjin, 1979; Mackinonn et al., 1991).

Como sinais de estresse térmico nos eqüinos podemos citar o aumento da freqüência respiratória, da freqüência cardíaca, sudorese, vasos periféricos aparentes na superfície corpórea e aumento da temperatura retal (Crabble, 1998). A temperatura retal nos permite avaliar se em condições de estresse térmico esses animais estão conseguindo manter sua temperatura dentro dos limites normais. Nos eqüinos a temperatura retal pode variar entre 37,2 e $38,2^{\circ} \mathrm{C}$ (Cunningham, 1999). As alterações nas freqüências cardíaca e respiratória permitem saber quais raças toleram melhor o calor dessa região. Alterações nas freqüências cardíaca e respiratória podem evidenciar tentativas orgânicas para sair da condição de estresse térmico a que esses animais estão submetidos. Nos eqüinos, a freqüência cardíaca normal em repouso pode variar entre 32 a 44 batimentos por minuto e a freqüência respiratória normal em repouso varia de 8 a 16 respirações por minuto (Cunningham, 1999).

O trato respiratório também contribui para perda de calor e água; em condições ideais de temperatura $\left(12^{\circ} \mathrm{C}\right)$ perdem $20 \%$ do calor corporal através da respiração. Quando expostos a altas temperaturas $\left(35^{\circ} \mathrm{C}\right)$, esta perda de calor latente via respiração chega até $60 \%$ do calor total perdido (Yousef, 1985).
$\mathrm{O}$ aumento na perda de calor pela via respiratória pode ser entendido como um mecanismo compensatório de perda de calor quando sua eliminação via sudorese atingiu seu nível máximo para as condições ambientais (Guthrie \& Lund, 1998).

Jain (1993) e Lassen \& Swardson (1995) propuseram que a leucocitose fisiológica normalmente ocorre em animais estressados, como sendo mediada principalmente pela liberação da epinefrina e de corticosteróides, levando à liberação de neutrófilos do compartimento marginal para a circulação periférica. Foram observados ainda, aumentos no volume globular (VG), hemoglobina e do número de hemácias em conseqüência da contração esplênica pela ação da epinefrina. Os aumentos no eritrograma podem ser evidenciados após 60 minutos da exposição ao estímulo estressante, dependendo da intensidade do mesmo.

A raça influencia a leucometria global, uma vez que em eqüinos PSC (sangue quente) a leucometria global varia de $7-14 \times 10^{3} / \mathrm{mL}$ (média de $10 \times 10^{3} / \mathrm{mL}$ ) enquanto eqüinos de tração possuem uma variação de $6-12 \times 10^{3} / \mathrm{mL}$ (média de $8,9 \times 10^{3} / \mathrm{mL}$ ). A hematimetria do cavalo de "sangue quente" excede em 2-3 milhões/mL as contagens do cavalo de sangue frio, pois os eritrócitos são menores, estando presentes em maior número por unidade de volume de sangue (Jain, 1993; Lassen \& Swardson, 1995).

Em animais adaptados aos climas quentes podemos observar maior taxa de sudorese, decréscimo na freqüência cardíaca, na temperatura central e cutânea (Cheung \& McLellan, 1998), denotando menor estresse sofrido por estes animais. Desse modo, mensuradas as freqüências cardíacas e respiratórias e a temperatura retal, bem como avaliados os valores hematológicos dos animais do Exército em Brasília, pode-se determinar quais das raças estudadas apresentam melhores adaptações ao Distrito Federal. O objetivo deste estudo foi determinar qual o efeito do estresse térmico e do exercício a que estão submetidas as raças de eqüinos estudadas (PSC, BH, Bretã e Mestiços), na região de Cerrado.

\section{Material e Métodos}

Foram utilizados 40 cavalos adultos (4 a 13 anos) do $1^{\circ}$ Regimento de Cavalaria de Guardas (RCG), Ministério da Defesa, Brasília, DF, sendo 10 animais de cada uma das raças: Puro Sangue de Corrida (PSC), Brasileiro de Hipismo (BH) e Mestiços (M), bem como 10 animais adultos da raça Bretã, per- 
tencentes ao $32^{\circ}$ Grupo de Artilharia de Campanha, Ministério da Defesa, Brasília, DF, mantidos nas mesmas dependências dos animais do RCG. Os animais permaneciam em baias, saindo no momento da execução dos exercícios. Recebiam alimentação concentrada ao meio dia e à meia noite, e volumoso durante à tarde.

O experimento foi do tipo switch-back (onde os cavalos expostos ao sol um dia ficam na sombra no dia seguinte), com três repetições, com intuito de eliminar o efeito entre período e cavalo. As características examinadas foram freqüência cardíaca (FC), freqüência respiratória (FR) e temperatura retal (TR) em quatro ocasiões durante o dia, sendo: 1) Nas baias (6h), temperatura ambiental 18 a $20^{\circ} \mathrm{C}$; 2) Depois de 20 minutos de galope na guia ( $7 \mathrm{~h} 30)$, temperatura ambiental 19 a $21^{\circ} \mathrm{C}$; 3) Após duas horas de exposição ao pleno sol (14h), temperatura ambiental 27 a $29^{\circ} \mathrm{C}$; (3b) Nas baias, às $14 \mathrm{~h}$, temperatura ambiental 26 a $29^{\circ} \mathrm{C}$; 4) Depois de 20 minutos de galope na guia no sol (14h30), temperatura ambiental 27 a $29^{\circ} \mathrm{C}$.

Foram colhidas amostras de sangue por venopunção jugular, em tubos à vácuo contendo EDTA para a

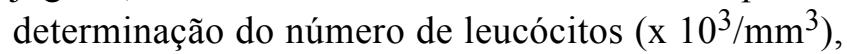
número de hemácias $\left(x 10^{6} / \mathrm{mm}^{3}\right)$, concentração de hemoglobina $(\mathrm{g} / \mathrm{dL})$, volume corpuscular médio - VCM (fl), hemoglobina corpuscular média - HCM (pg), concentração de hemoglobina corpuscular média $\mathrm{CHCM}(\%)$, por intermédio de um contador automático de células para uso veterinário. O volume globular VG (\%) foi obtido com auxílio de uma microcentrífuga. A concentração da proteína plasmática total - PT ( $\mathrm{g} / \mathrm{dL}$ ) foi determinada com auxílio de um refratômetro.

Submeteram-se os dados coletados à análise de variância, conforme o modelo matemático:

$$
\mathrm{Y}_{\mathrm{ijklmn}}=\mu+\mathrm{C}_{\mathrm{i}}+\mathrm{A}_{\mathrm{j}}+\mathrm{D}_{\mathrm{k}}+\mathrm{T}_{1}+\mathrm{R}_{\mathrm{m}}+\mathrm{RT}_{\mathrm{lm}}+\mathrm{e}_{\mathrm{ijklmn}}
$$
em que: Yijklmn = observação do indivíduo 1; $\mu=$ constante; $C_{i}=$ efeito de conjunto de cavalos, $\mathrm{C}_{\mathrm{i}} \sim \mathrm{NID}\left(0, \sigma_{\mathrm{c}}^{2}\right) ; \mathrm{Aj}=$ efeito do animal dentro de conjunto, $\mathrm{Ai} \sim \mathrm{NID}(0, \mathrm{~s} 2 \mathrm{~A}) ; \mathrm{D}_{\mathrm{k}}=$ efeito fixo do dia de medida, $\mathrm{k}=1,2$ ou $3 ; \mathrm{T}_{1}=$ efeito fixo de tratamento, $1=1,2,3,3$ b ou $4 ; R_{m}=$ efeito fixo de raça de cavalo, $\mathrm{m}=$ Puro Sangue de Corrida (PSC), Brasileiro de Hipismo (BH), Mestiço (M) e Bretã (B); $\mathrm{TR}_{1 \mathrm{~m}}=$ interação entre raça e tratamento; $\mathrm{e}_{\mathrm{ijkl}}=$ erro aleatório associado a cada observação, suposto normalmente distribuído e independente, com média zero e variância $\sigma^{2}$. Opeso do animal e idade foram investigadas como covariáveis (linear e quadrática) mas não foram significativas sendo retiradas do modelo.
As correlações (r) foram analisadas usando a seguinte fórmula:

$$
r=\frac{\operatorname{cov}(X, Y)}{\sqrt{\operatorname{var}(X) \operatorname{var}(Y)}}
$$

em que: $\operatorname{cov}(X, Y)=$ covariância entre variável $X$ e variável $\mathrm{Y}$, $\operatorname{var}(\mathrm{X})$ ou $\operatorname{var}(\mathrm{Y})$ = variância de característica $\mathrm{X}$ ou $\mathrm{Y}$.

A técnica dos componentes principais consiste em transformar o conjunto de $\mathrm{v}$ variáveis em um novo conjunto, que é função linear das funções originais e independentes entre si. Componentes principais são usados para reduzir o número de variáveis e detectar a relação entre eles. A técnica é baseada na maximização do espaço original de variação e o alvo da rotação é maximizar a variação da nova variável (componente) enquanto minimiza a variância em volta da nova variável (Joliffe, 1986). Entre todos os componentes, o primeiro apresenta a maior variância, o segundo componente tem a segunda maior variância e, assim, sucessivamente.

O programa estatístico Statistical Analysis System (SAS, 1999) foi usado para realizar as análises.

\section{Resultados e Discussão}

As médias das características fisiológicas e hematológicas por raça e tratamento estão na Tabelas 1 e 2 respectivamente, com o resumo da análise de variância dos parâmetros fisiológicos na Tabela 3. A raça e o tratamento influenciaram as características estudadas. Além disso, observa-se uma interação entre raça e tratamento. Os modelos explicaram entre 56 e $64 \%$ da variação das características. As TR, FC e FR diferiram entre os animais em repouso e em exercício, bem como para os animais em repouso de manhã e a tarde sendo que para os animais expostos à temperatura ambiental mais elevada ou após esforço físico houve índices maiores para todos os parâmetros. Dentre os animais em repouso à tarde, aqueles expostos ao sol tiveram FR maiores, contudo FC e TR não diferiram $(p>0,05)$. Os animais em exercício (de manhã e à tarde) não apresentaram diferenças $(\mathrm{p}>0,05)$ em termos de FC e TR, mas à tarde a FR foi maior $(p<0,01)$. O efeito do conjunto de animais em cada tratamento por dia não foi significativo para as características estudadas, mas houve diferenças significativas entre os animais dentro do conjunto.

As comparações (via contrastes ortogonais) dentro

R. Bras. Zootec., v.31, n.3, p.1130-1142, 2002 
de cada raça estão apresentadas na Tabela 3, com os resultados por raça apresentados nas Tabelas 4, 5, 6 e 9. A partir destas comparações, verifica-se que as raças se comportaram de maneira diferente. Para todas as raças e todos os parâmetros o estado do animal (em repouso ou exercício) determinou uma diferença significativa. Comparando os animais em repouso de manhã e a tarde podemos verificar que para as raças Bretã, PSC e mestiço as TR foram diferentes $(p<0,05)$. Comparando os animais nas baias com aqueles expostos ao sol à tarde, apenas os animais mestiços mostraram diferenças significativas quanto à FR e FC. Quando analisados os animais em exercício de manhã e à tarde, observou-se que FC dos Bretões foi mais baixa à tarde, FR do PSC também foi mais alta à tarde e os três parâmetros (FR, FC, TR) dos mestiços foram significativamente maiores à tarde.

Pode-se observar que, em geral, os coeficientes de variação estão entre 11 e $25 \%$, enquanto FR é mais elevada, o que pode ser explicado uma vez que a FR é a primeira linha de defesa fisiológica quando aumenta o estresse térmico ou por exercício, denotando maior variação.
Conforme apresentado na Tabela 1, pode-se observar que a $\mathrm{FC}$ média dos animais em repouso não diferenciou $(p>0,05)$ entre os grupos, independentemente da exposição ao sol. A raça $\mathrm{BH}$ mostrou uma $\mathrm{FC}$ superior $(\mathrm{p}<0,05)$ às outras raças, que não diferiram entre si. Na mesma região McManus \& Miranda (1997) também acharam um efeito significativo de raça para tolerância ao calor em ovinos bem como para bovinos (McManus et al., 1999).

A FR média de manhã cedo $(7 \mathrm{~h})$ foi inferior à dos outros horários (Tabela 1). Os animais em repouso, no sol e nas baias, não apresentaram diferenças significativas de FR, contudo essas médias foram diferentes dos outros horários. As médias após os exercícios foram mais altas que em repouso, contudo houve diferenças significativas entre as médias da manhã e da tarde, mostrando que a temperatura do ambiente influenciou no aumento da FR. Em termos de raças, o PSC teve menor FR, mas não foi significativamente diferente dos $\mathrm{BH}$ e Mestiços. A Bretã teve maior FR, mas não foi significativamente diferente entre $\mathrm{BH}$ e Mestiço.

As médias das TR (Tabela 1) para os animais nas baias (de manhã e à tarde) não foram diferentes entre

Tabela 1 - Médias e desvios-padrão dos parâmetros fisiológicos em cavalos do Exército Brasileiro Table 1 - Means and standard deviation of physiological parameters in horses of the Brazilian army

\begin{tabular}{|c|c|c|c|c|c|c|}
\hline $\begin{array}{l}\text { Caract. } \\
\text { Trait }\end{array}$ & TRAT & $\mathrm{BH}$ & Bretã & PSC & $\begin{array}{l}\text { Mestiço } \\
\text { Crossbred }\end{array}$ & Média \\
\hline \multirow[t]{5}{*}{$\mathrm{FC}$} & 1 & $40,83 \pm 4,71^{\mathrm{a}}$ & $32,12 \pm 3,77^{\mathrm{a}}$ & $34,46 \pm 3,26^{\mathrm{a}}$ & $33,76 \pm 1,94^{\mathrm{a}}$ & $35,67 \pm 4,96$ \\
\hline & 2 & $53,67 \pm 8,24^{b}$ & $52,00 \pm 10,47^{b}$ & $45,67 \pm 10,12^{b}$ & $48,11 \pm 6,60^{\mathrm{b}}$ & $49,44 \pm 9,12$ \\
\hline & 3 & $40,80 \pm 7,16^{\mathrm{a}}$ & $34,67 \pm 3,55^{\mathrm{a}}$ & $36,11 \pm 3,89^{\mathrm{a}}$ & $41,75 \pm 5,80^{\mathrm{c}}$ & $37,62 \pm 5,54$ \\
\hline & $3 b$ & $41,78 \pm 4,60^{\mathrm{a}}$ & $32,86 \pm 5,70^{\mathrm{a}}$ & $38,00 \pm 1,63^{\mathrm{ac}}$ & $34,80 \pm 3,99^{a}$ & $36,98 \pm 5,90$ \\
\hline & 4 & $58,67 \pm 8,64^{b}$ & $45,33 \pm 9,55^{b}$ & $44,22 \pm 4,29^{b c}$ & $52,44 \pm 8,23^{\mathrm{d}}$ & $49,05 \pm 9,41$ \\
\hline Média raça & & $44,24 \pm 8,32$ & $37,81 \pm 9,72$ & $39,41 \pm 7,17$ & $39,47 \pm 8,60$ & \\
\hline \multirow[t]{5}{*}{ FR } & 1 & $16,67 \pm 3,05^{\mathrm{a}}$ & $19,67 \pm 3,60^{\mathrm{a}}$ & $13,85 \pm 2,34^{\mathrm{a}}$ & $12,72 \pm 3,26^{\mathrm{a}}$ & $15,32 \pm 3,96$ \\
\hline & 2 & $37,33 \pm 11.5^{b}$ & $34,00 \pm 6,05^{b}$ & $22,56 \pm 7,80^{\mathrm{bc}}$ & $24,22 \pm 5,61^{b}$ & $28,66 \pm 9,58$ \\
\hline & 3 & $17,60 \pm 2,19^{a}$ & $24,67 \pm 3,34^{\mathrm{a}}$ & $18,67 \pm 8,37^{\mathrm{ac}}$ & $36,75 \pm 2,04^{\mathrm{c}}$ & $24,88 \pm 12,74$ \\
\hline & $3 b$ & $18,22 \pm 2,82^{\mathrm{a}}$ & $23,42 \pm 5,40^{\mathrm{a}}$ & $16,00 \pm 2,31^{\mathrm{ac}}$ & $20,27 \pm 9,47^{a b}$ & $20,08 \pm 12,74$ \\
\hline & 4 & $41,67 \pm 8,24^{b}$ & $32,67 \pm 9,62^{b}$ & $30,89 \pm 10,78^{b}$ & $42,44 \pm 26,0^{\mathrm{c}}$ & $36,17 \pm 15,70$ \\
\hline Média raça & & $21,86 \pm 10,28$ & $26,28 \pm 7,90$ & $20,29 \pm 9,34$ & $22,97 \pm 16,53$ & \\
\hline \multirow[t]{5}{*}{$\mathrm{TR}$} & 1 & $37,64 \pm 0,21^{\mathrm{a}}$ & $37,76 \pm 0,12^{\mathrm{a}}$ & $37,86 \pm 0,19^{\mathrm{a}}$ & $37,56 \pm 0,26^{\mathrm{a}}$ & $37,67 \pm 0,24$ \\
\hline & 2 & $38,15 \pm 0,41^{\mathrm{b}}$ & $38,19 \pm 0,17^{\mathrm{b}}$ & $38,24 \pm 0,40^{\mathrm{b}}$ & $38,04 \pm 0,37^{\mathrm{b}}$ & $38,16 \pm 0,34$ \\
\hline & 3 & $37,82 \pm 0,28^{\mathrm{ab}}$ & $37,64 \pm 0,19^{\mathrm{a}}$ & $38,08 \pm 0,43^{\mathrm{ab}}$ & $38,40 \pm 0,45^{\mathrm{c}}$ & $37,96 \pm 0,45$ \\
\hline & $3 b$ & $37,72 \pm 0,29^{\mathrm{ab}}$ & $37,59 \pm 0,24^{\mathrm{a}}$ & $38,25 \pm 0,55^{\mathrm{b}}$ & $37,63 \pm 0,37^{\mathrm{a}}$ & $37,70 \pm 0,36$ \\
\hline & 4 & $37,96 \pm 0,55^{\mathrm{ab}}$ & $38,18 \pm 0,36^{\mathrm{b}}$ & $38,30 \pm 0,40^{\mathrm{b}}$ & $38,69 \pm 0,47^{\mathrm{c}}$ & $38,31 \pm 0,48$ \\
\hline Média raça & & $37,74 \pm 0,32$ & $37,84 \pm 0,34$ & $38,11 \pm 0,40$ & $37,90 \pm 0,55$ & \\
\hline
\end{tabular}

Números com letras diferentes são significativamente diferentes segundo teste de Tukey, a $5 \%$.

TRAT 1 - nas baias às $6 \mathrm{~h}$, TRAT 2 - após o exercício às $7 \mathrm{~h} 30$, TRAT 3 - após exposição ao sol às $14 \mathrm{~h}$, TRAT $3 \mathrm{~b}$ - animais conservados nas baias, TRAT 4 - após exercício no sol às $14 \mathrm{~h} 30$, CARACT - característica, TRAT - tratamento, FC - freqüência cardíaca, FR - freqüência respiratória, TR - temperatura retal, BH - brasileiro de hipismo, PSC - Puro Sangue de Corrida.

Numbers with different letters are significantly different (Tukey test) at $5 \%$ level.

TRAT 1 - in stable at 6a.m., TRAT 2 - after exercise at 7h30 a.m., TRAT 3 - after exposure to sun at 2p.m., TRAT 3b - stabled at 2p.m., TRAT 4 - after exercise in sun at 2:30p.m., CARACT-characteristic, TRAT-treatment, FC-heartbeat, FR-breathing rate, TR-rectaltemperature, BH-Brazilian showjumper, PSC-thoroughbred.

R. Bras. Zootec., v.31, n.3, p.1130-1142, 2002 
si, mostrando que o aumento na temperatura do ambiente não resultou em aumento na TR, enquanto os animais expostos ao sol tiveram um aumento na TR $(\mathrm{p}<0,05)$. Isto concorda com Bond (1967) que afirmou que durante períodos de estresse, um animal no sol está exposto a uma carga radiante maior de que a sua produção de calor metabólica, influenciando na elevação da TR. A raça PSC apresentou médias de TR mais altas $(p<0,05)$ do que as outras raças. As raças BH e Bretã tiveram médias mais baixas, mas a média da Bretã não foi diferente do mestiço. Em termos de adaptação, se considerarmos a TR, pode-se afirmar que o BH e a Bretã são os animais mais bem adaptados, enquanto o PSC, o menos adaptado e o mestiço, de adaptação intermediária. Em um trabalho combovinos, Kellaway \& Colditz(1975) verificaram que as FR e TR de animais B. taurus puros foram significativamente maiores quando comparadas aos animais cru-

Tabela 2 - Médias e desvios-padrão dos parâmetros hematológicos em cavalos do Exército Brasileiro Table 2 - Means and standard deviation of hematological parameters in horses of the Brazilian army

\begin{tabular}{|c|c|c|c|c|c|c|}
\hline Caract. & TRAT & $\mathrm{BH}$ & Bretã & PSC & Mestiço & Média \\
\hline \multicolumn{7}{|l|}{ LEU } \\
\hline & 1 & $7,58 \pm 1,44^{\mathrm{a}}$ & $6,41 \pm 0,96^{\mathrm{a}}$ & $7,11 \pm 1,50^{\mathrm{a}}$ & $5,87 \pm 1,34^{\mathrm{ac}}$ & $6,79 \pm 1,49$ \\
\hline & 2 & $7,58 \pm 1,25^{\mathrm{a}}$ & $6,46 \pm 1,42^{\mathrm{a}}$ & $7,74 \pm 1,15^{\mathrm{ab}}$ & $7,25 \pm 1,96^{\mathrm{b}}$ & $7,33 \pm 1,51$ \\
\hline & 3 & $7,44 \pm 1,10^{\mathrm{a}}$ & $6,51 \pm 1,11^{\mathrm{a}}$ & $7,78 \pm 1,81^{a b}$ & $7,04 \pm 2,23^{\mathrm{ab}}$ & $7,16 \pm 1,69$ \\
\hline & $3 b$ & $9,71 \pm 2,04^{b}$ & $*$ & $*$ & $5,25 \pm 1,06^{\mathrm{c}}$ & $8,54 \pm 2,55$ \\
\hline & 4 & $9,0 \pm 1,53^{\mathrm{ab}}$ & $7,12 \pm 1,77^{\mathrm{a}}$ & $8,7 \pm 1,66^{\mathrm{b}}$ & $7,97 \pm 2,47^{b}$ & $8,20 \pm 1,97$ \\
\hline Média raça & & $8,16 \pm 1,68$ & $6,67 \pm 1,28$ & $7,83 \pm 1,59$ & $6,89 \pm 2,07$ & \\
\hline \multicolumn{7}{|l|}{ HEM } \\
\hline & 1 & $7,47 \pm 1,18^{\mathrm{a}}$ & $6,59 \pm 0,72^{\mathrm{a}}$ & $8,46 \pm 0,78^{a}$ & $7,42 \pm 0,96^{\mathrm{a}}$ & $7,55 \pm 1,11$ \\
\hline & 2 & $9,64 \pm 2,68^{b}$ & $7,08 \pm 0,96^{a}$ & $9,55 \pm 0,85^{\mathrm{ab}}$ & $8,46 \pm 1,26^{\mathrm{b}}$ & $8,78 \pm 1,67$ \\
\hline & 3 & $7,69 \pm 1,06^{\mathrm{ab}}$ & $7,20 \pm 2,52^{a}$ & $8,99 \pm 1,94^{\mathrm{ab}}$ & $8,10 \pm 1,76^{a b}$ & $8,03 \pm 2,01$ \\
\hline & $3 b$ & $7,56 \pm 0,70^{a b}$ & $*$ & $*$ & $7,81 \pm 0,48^{a b}$ & $7,59 \pm 0,60$ \\
\hline & 4 & $8,39 \pm 0,82^{a b}$ & $7,53 \pm 0,92^{a}$ & $9,84 \pm 0,85^{b}$ & $8,97 \pm 0,40^{\mathrm{b}}$ & $8,80 \pm 1,13$ \\
\hline Média raça & & $7,99 \pm 1,51$ & $7,13 \pm 1,55$ & $9,21 \pm 1,27$ & $8,18 \pm 1,26$ & \\
\hline \multicolumn{7}{|l|}{$\mathrm{HB}$} \\
\hline & 1 & $11,80 \pm 1,82^{\mathrm{a}}$ & $10,40 \pm 0,63^{\mathrm{a}}$ & $12,96 \pm 0,88^{\mathrm{a}}$ & $11,76 \pm 0,83^{\mathrm{a}}$ & $11,84 \pm 1,43$ \\
\hline & 2 & $13,02 \pm 0,83^{a}$ & $11,10 \pm 0,66^{\mathrm{ab}}$ & $14,89 \pm 1,79 \mathrm{bc}$ & $15,58 \pm 1,61^{b}$ & $14,10 \pm 2,17$ \\
\hline & 3 & $11,38 \pm 0,27^{\mathrm{a}}$ & $10,88 \pm 1,18^{\mathrm{ab}}$ & $13,71 \pm 1,15^{\mathrm{ac}}$ & $12,79 \pm 1,41^{\mathrm{a}}$ & $12,29 \pm 1,61$ \\
\hline & $3 b$ & $11,48 \pm 0,98^{a}$ & $*$ & $*$ & $12,40 \pm 0,42^{\mathrm{a}}$ & $11,66 \pm 0,90$ \\
\hline & 4 & $13,24 \pm 0,54^{\mathrm{a}}$ & $12,28 \pm 1,21^{b}$ & $15,81 \pm 1,25^{b}$ & $15,16 \pm 1,49^{b}$ & $14,43 \pm 1,84$ \\
\hline Média raça & & $12,08 \pm 1,40$ & $11,14 \pm 1,14$ & $14,34 \pm 1,67$ & $13,65 \pm 2,05$ & \\
\hline \multicolumn{7}{|l|}{ VG } \\
\hline & 1 & $30,58 \pm 9,51^{\mathrm{a}}$ & $32,17 \pm 5,78^{a}$ & $36,89 \pm 2,80^{\mathrm{a}}$ & $34,45 \pm 2,21^{\mathrm{a}}$ & $33,45 \pm 6,37$ \\
\hline & 2 & $39,60 \pm 5,03^{a}$ & $31,60 \pm 2,30^{\mathrm{a}}$ & $42,67 \pm 4,33^{b}$ & $45,11 \pm 3,55^{b}$ & $40,93 \pm 6,09$ \\
\hline & 3 & $32,80 \pm 0,84^{\mathrm{a}}$ & $29,11 \pm 3,55^{\mathrm{a}}$ & $39,11 \pm 3,95^{\mathrm{a}}$ & $35,33 \pm 4,53^{\mathrm{a}}$ & $34,25 \pm 5,28$ \\
\hline & $3 b$ & $32,00 \pm 3,52^{\mathrm{a}}$ & $*$ & $*$ & $35,00 \pm 0^{\mathrm{a}}$ & $32,67 \pm 3,08$ \\
\hline & 4 & $37,40 \pm 0,55^{a}$ & $34,28 \pm 3,04^{\mathrm{a}}$ & $44,33 \pm 3,35^{b}$ & $44,00 \pm 2.96^{b}$ & $40,73 \pm 5,17$ \\
\hline Média raça & & $33,56 \pm 6,94$ & $31,61 \pm 4,09$ & $40,75 \pm 4,58$ & $39,23 \pm 5,82$ & \\
\hline \multicolumn{7}{|l|}{ PT } \\
\hline & 1 & $6,01 \pm 0,54^{\mathrm{a}}$ & $6,33 \pm 0,42^{\mathrm{a}}$ & $6,07 \pm 0,63^{\mathrm{a}}$ & $6,71 \pm 0,37^{\mathrm{a}}$ & $6,28 \pm 0,57$ \\
\hline & 2 & $6,42 \pm 0,65^{\mathrm{a}}$ & $6,44 \pm 0,30^{\mathrm{a}}$ & $6,59 \pm 0,68^{a}$ & $7,09 \pm 0,45^{\mathrm{ab}}$ & $6,69 \pm 0,59$ \\
\hline & 3 & $6,70 \pm 0,91^{\mathrm{a}}$ & $6,50 \pm 0,75^{a}$ & $6,28 \pm 0,71^{\mathrm{a}}$ & $6,62 \pm 0,74^{\mathrm{a}}$ & $6,50 \pm 0,74$ \\
\hline & $3 b$ & $6,77 \pm 1,02^{a}$ & * & $*$ & $6,50 \pm 0,14^{\mathrm{ab}}$ & $6,64 \pm 0,83$ \\
\hline & 4 & $6,74 \pm 1,11^{\mathrm{a}}$ & $6,99 \pm 1,08^{a}$ & $6,70 \pm 0,77^{\mathrm{a}}$ & $7,42 \pm 0,81^{b}$ & $6,99 \pm 0,92$ \\
\hline Média raça & & $6,42 \pm 0,83$ & $6,56 \pm 0,73$ & $6,41 \pm 0,71$ & $6,93 \pm 0,66$ & \\
\hline
\end{tabular}

Números com letras diferentes são significativamente diferentes segundo teste de Tukey, a $5 \%$.

TRAT 1 - nas baias às $6 \mathrm{~h}$, TRAT 2 - após o exercício às $7 \mathrm{~h} 30$, TRAT 3 - após exposição ao sol às $14 \mathrm{~h}$, TRAT $3 \mathrm{~b}$ - animais conservados nas baias, TRAT 4 - Após exercício no sol às $14 \mathrm{~h} 30$, CARACT - característica, TRAT - tratamento, LEUC - leucócitos $\left(\times 10^{3} / \mathrm{mm}^{3}\right)$, HEM - hemácias $\left(\times 10^{6} / \mathrm{mm}^{3}\right)$, HB - Hemoglobina ( $\left./ \mathrm{dL}\right)$, VG(\%), PT - Proteína Plasmática Total (g/dL), BH - brasileiro de hipismo, PSC - Puro Sangue de Corrida, * não foram coletados dados.

Numbers with different letters are significantly different (Tukey test) at $5 \%$ level.

TRAT 1 - in stable at 6a.m., TRAT 2 - after exercise at 7:30a.m., TRAT 3- after exposure to sun at 2p.m., TRAT 3b-atabled at 2p.m., TRAT 4- after exercise in sun at 2:30p.m., CARACT - characteristic, TRAT-treatment, LEUC - leukocytes $\left(\times 10^{3} / \mathrm{mm}^{3}\right), \mathrm{HEM}-\mathrm{Hemacias}\left(\times 10^{6} / \mathrm{mm}^{3}\right), \mathrm{HB}-\mathrm{Hemog} / \mathrm{obin}(\mathrm{g} / \mathrm{dL})$, VG - globular volume(\%), PT - total protein ( $\mathrm{mg} / \mathrm{dL}$ ), s - standard deviation, cv - coefficient of variation, BH - Brazilian showjumper, PSC - thoroughbred, PSC - thoroughbred, " there are no data.

\section{R. Bras. Zootec., v.31, n.3, p.1130-1142, 2002}


Tabela 3 - Análise de variância dos parâmetros fisiológicos dos cavalos Brasileiros de Hipismo do Exército Brasileiro Table 3 - Variance analysis for physiological parameters in Brazilian showjumper horses in the Brazilian Army

\begin{tabular}{|c|c|c|c|c|c|c|c|c|c|c|c|}
\hline & $\mathrm{FC}$ & FR & $\mathrm{TR}$ & LEUC & $\mathrm{HB}$ & $\mathrm{HCM}$ & CHCM & HEM & $\mathrm{VG}$ & VCM & PT \\
\hline Idade & $\mathrm{ns}$ & $\mathrm{ns}$ & $\mathrm{ns}$ & $\mathrm{ns}$ & $\mathrm{ns}$ & $\mathrm{ns}$ & $\mathrm{ns}$ & $\mathrm{ns}$ & $\mathrm{ns}$ & $\mathrm{ns}$ & $\mathrm{ns}$ \\
\hline Cor & $\mathrm{ns}$ & $\mathrm{ns}$ & $\mathrm{ns}$ & $\mathrm{ns}$ & $\mathrm{ns}$ & ns & $\mathrm{ns}$ & $\mathrm{ns}$ & $\mathrm{ns}$ & $\mathrm{ns}$ & $\mathrm{ns}$ \\
\hline Data & $*$ & $\mathrm{~ns}$ & $* *$ & $\mathrm{~ns}$ & $\mathrm{~ns}$ & $\mathrm{~ns}$ & $\mathrm{~ns}$ & $\mathrm{~ns}$ & $\mathrm{~ns}$ & $\mathrm{~ns}$ & $\mathrm{~ns}$ \\
\hline Grp & $* *$ & $* *$ & $*$ & $*$ & $*$ & $\mathrm{~ns}$ & $\mathrm{~ns}$ & $*$ & $\mathrm{~ns}$ & $\mathrm{~ns}$ & $*$ \\
\hline Peso & $\mathrm{ns}$ & $\mathrm{ns}$ & $\mathrm{ns}$ & $\mathrm{ns}$ & $\mathrm{ns}$ & $\mathrm{ns}$ & $\mathrm{ns}$ & $\mathrm{ns}$ & $\mathrm{ns}$ & $\mathrm{ns}$ & $\mathrm{ns}$ \\
\hline \multicolumn{12}{|c|}{ Contrastes } \\
\hline \multicolumn{12}{|c|}{ Contrasts } \\
\hline 1 & $* *$ & $* *$ & $*$ & $* *$ & $* *$ & $\mathrm{~ns}$ & $\mathrm{~ns}$ & $* *$ & $\mathrm{~ns}$ & $\mathrm{~ns}$ & $\mathrm{~ns}$ \\
\hline 2 & $\mathrm{~ns}$ & $\mathrm{~ns}$ & $\mathrm{~ns}$ & $*$ & $\mathrm{~ns}$ & $\mathrm{~ns}$ & $\mathrm{~ns}$ & $\mathrm{~ns}$ & $\mathrm{~ns}$ & $\mathrm{~ns}$ & $\mathrm{~ns}$ \\
\hline 3 & $\mathrm{~ns}$ & $\mathrm{~ns}$ & $\mathrm{~ns}$ & $*$ & $\mathrm{~ns}$ & $\mathrm{~ns}$ & $\mathrm{~ns}$ & $\mathrm{~ns}$ & $\mathrm{~ns}$ & $\mathrm{~ns}$ & $*$ \\
\hline 4 & $\mathrm{~ns}$ & $\mathrm{~ns}$ & $\mathrm{~ns}$ & $\mathrm{~ns}$ & $\mathrm{~ns}$ & ns & $\mathrm{ns}$ & $\mathrm{ns}$ & $\mathrm{ns}$ & $\mathrm{ns}$ & $\mathrm{ns}$ \\
\hline 5 & $\mathrm{~ns}$ & $\mathrm{~ns}$ & $\mathrm{~ns}$ & $*$ & $\mathrm{~ns}$ & $\mathrm{~ns}$ & $\mathrm{~ns}$ & $\mathrm{~ns}$ & $\mathrm{~ns}$ & $\mathrm{~ns}$ & $\mathrm{~ns}$ \\
\hline 6 & $* *$ & $* *$ & $\mathrm{~ns}$ & $\mathrm{~ns}$ & $*$ & $\mathrm{~ns}$ & $\mathrm{~ns}$ & $\mathrm{~ns}$ & $\mathrm{~ns}$ & $\mathrm{~ns}$ & $\mathrm{~ns}$ \\
\hline 7 & $* *$ & $* *$ & $*$ & $\mathrm{~ns}$ & $* *$ & $\mathrm{~ns}$ & $\mathrm{~ns}$ & $* *$ & $\mathrm{~ns}$ & $\mathrm{~ns}$ & $\mathrm{~ns}$ \\
\hline 8 & $\mathrm{~ns}$ & $\mathrm{~ns}$ & $\mathrm{~ns}$ & $\mathrm{~ns}$ & $\mathrm{~ns}$ & $\mathrm{~ns}$ & $\mathrm{~ns}$ & $\mathrm{~ns}$ & $\mathrm{~ns}$ & $\mathrm{~ns}$ & $\mathrm{~ns}$ \\
\hline $\mathrm{R}^{2}$ & 0,64 & 0,78 & 0,38 & 0,71 & 0,34 & 0,31 & 0,27 & 0,44 & 0,46 & 0,13 & 0,52 \\
\hline $\mathrm{CV}$ & 12,97 & 23,98 & 0,73 & 12,95 & 11,06 & 13,78 & 179,83 & 16,6 & 17,7 & 23,95 & 10,47 \\
\hline Média & 44,24 & 21,86 & 37,74 & 8,16 & 12,08 & 15,78 & 51,16 & 7,98 & 33,57 & 42,56 & 6,42 \\
\hline
\end{tabular}

${ }^{* *} \mathrm{P}<0,01$; * $\mathrm{P}<0,05$, ns - não-significativo, $C V$ - coeficiente de variação, $R^{2}$ - coeficiente de determinação, $X$ - média, FC - freqüência cardíaca, FR - freqüência respiratória, TR - temperatura retal, LEUC - leucócitos $\left(x 10^{3} / \mathrm{mm}^{3}\right)$, HEM - hemácias $\left(\times 10^{6} / \mathrm{mm}^{3}\right)$, $\mathrm{HB}$ - Hemoglobina (g/dL), VG (\%), VCM (fl), HCM (pg), CHCM (\%), PT - proteína plasmática total (g/dL). Contrastes: 1 - repouso versus exercício, independentemente de horário, 2 - manhã versus tarde em repouso 3 - baia versus sol à tarde, 4 - exercício (manhã versus tarde), 5 - manhã versus tarde, independentemente de exercício, 6 - exercício versus repouso de manhã, 7 - exercício versus repouso à tarde, 8 - baia versus sol à tarde.

** $P<.01$; * $P<.05$, ns - not significant, CV - coefficient of variation, $R^{2}$ - coefficient of determination, $X$ - mean, FC - heart beat, FR - breathing rate, TR - rectal temperature, LEUC - leukocytes $\left(\times 10^{3} / \mathrm{mm}^{3}\right)$, HEM - Hemacias (x 106/ $\left.\mathrm{mm}{ }^{3}\right), H B$ - Hemoglobin (g/dL), VG - globular volume(\%), VCM - mean corpuscular volume (fl), HCM - mean corpuscular hemoglobin (pg), CHCM - concentration of mean corpuscular hemoglobin (\%), PROT-total protein (mg/dL); CONTRASTS: 1 - rest versus exercise independent of time, 2 - morning versus afternoon at rest; 3 - stall versus sun in afternoon; 4 - exercise (morning versus afternoon), 5 - morning versus afternoon independent of exercise, 6 - exercise versus rest afternoon, 7 - exercise versus rest afternoon, 8 - stall versus sun afternoon.

zados Holandês-Zebu e sua ingestão de água também foi maior em condições de estresse. Neste trabalho a vantagem dos animais cruzados não está tão clara.

Se considerarmos, em termos de adaptação, a FC, FR e TR, os animais BH foram os menos afetados pelo ambiente, seguidos pelos Bretões e os PSC, sendo os menos adaptados os mestiços, que foram altamente influenciados pelos fatores de exposição ao sol, temperatura ambiental e exercícios.

O peso não foi um fator importante nas características fisiológicas estudadas. As médias dos pesos foram $410,48( \pm 9,74), 531,88( \pm 31,32), 410( \pm 55,21)$ e $380,12( \pm 18,94) \mathrm{kg}$ para as raças BH, Bretã, PSC e Mestiços, respectivamente, com uma média de $423,06( \pm 69,64) \mathrm{kg}$. A variação dentro de cada raça foi muito baixa. Cabe salientar que foram utilizados os mesmos animais em todos os tratamentos e, desta forma o erro experimental foi reduzido.

O exercício gerou alterações significativas nos parâmetros hematológicos. Este foi responsável pelo aumento geral do leucograma em $8,7 \%$, do VG em $17 \%$, da concentração de PT em $6 \%$, da hemoglobina em $16 \%$ e, principalmente, de hemácias em $15 \%$. Alguns valores não sofreram influências significativas: CHCM, VCM e HCM pois são obtidos a partir de cálculos onde são utilizados os valores de VG, hemácias e HB e, como estes aumentaram proporcionalmente, não determinaram variações nos demais.

Os eqüinos, segundo o estudo, que apresentaram maior quantidade de leucócitos no sangue, foram os $\mathrm{BH}$, seguidos do PSC, enquanto os Bretões obtiveram médias mais baixas. Foi observada também uma variação entre as amostras coletadas, com um aumento, em todas as raças, no número de leucócitos após sua permanência ao sol. Tais aumentos no número de leucócitos podem ser considerados fisiológicos, pois são resultantes do aumento da pressão sangüínea, aumento da freqüência cardíaca e da contração esplênica, devido à ação da epinefrina e do cortisol, liberados em situações de medo, excitação 
Tabela 4 - Análise de variância dos parâmetros fisiológicos dos cavalos puro sangue inglês do Exército Brasileiro Table 4 - Variance analysis for physiological parameters in thoroughbred horses in the Brazilian Army

\begin{tabular}{|c|c|c|c|c|c|c|c|c|c|c|c|}
\hline & $\mathrm{FC}$ & FR & $\mathrm{TR}$ & LEUC & HEMO & $\mathrm{HCM}$ & $\mathrm{CHCM}$ & HEM & VG & VCM & PT \\
\hline Idade & $\mathrm{ns}$ & $\mathrm{ns}$ & $\mathrm{ns}$ & $\mathrm{ns}$ & $\mathrm{ns}$ & $\mathrm{ns}$ & $\mathrm{ns}$ & $\mathrm{ns}$ & $\mathrm{ns}$ & $\mathrm{ns}$ & $\mathrm{ns}$ \\
\hline Cor & $\mathrm{ns}$ & $\mathrm{ns}$ & $\mathrm{ns}$ & $\mathrm{ns}$ & $\mathrm{ns}$ & $\mathrm{ns}$ & $\mathrm{ns}$ & $\mathrm{ns}$ & $\mathrm{ns}$ & $\mathrm{ns}$ & $\mathrm{ns}$ \\
\hline Data & ns & $* *$ & $* *$ & ns & $\mathrm{ns}$ & $* *$ & $\mathrm{~ns}$ & $\mathrm{~ns}$ & $\mathrm{~ns}$ & $\mathrm{~ns}$ & $* *$ \\
\hline Grp & $* *$ & $* *$ & $* *$ & $* *$ & $* *$ & $\mathrm{~ns}$ & $\mathrm{~ns}$ & $\mathrm{~ns}$ & $* *$ & $\mathrm{~ns}$ & $\mathrm{~ns}$ \\
\hline Peso & $\mathrm{ns}$ & $\mathrm{ns}$ & ns & $\mathrm{ns}$ & ns & $\mathrm{ns}$ & $\mathrm{ns}$ & ns & ns & $\mathrm{ns}$ & $\mathrm{ns}$ \\
\hline \multicolumn{12}{|c|}{ Contrastes } \\
\hline \multicolumn{12}{|c|}{ Contrasts } \\
\hline 1 & $* *$ & $* *$ & $\mathrm{~ns}$ & $\mathrm{~ns}$ & $\mathrm{~ns}$ & $\mathrm{~ns}$ & $\mathrm{~ns}$ & $\mathrm{~ns}$ & ns & $\mathrm{ns}$ & $\mathrm{ns}$ \\
\hline 2 & $\mathrm{~ns}$ & $* *$ & $\mathrm{~ns}$ & $\mathrm{~ns}$ & $\mathrm{~ns}$ & $\mathrm{~ns}$ & $\mathrm{~ns}$ & $\mathrm{~ns}$ & ns & $\mathrm{ns}$ & $\mathrm{ns}$ \\
\hline 3 & $\mathrm{~ns}$ & $\mathrm{~ns}$ & $*$ & $* *$ & $* *$ & $\mathrm{~ns}$ & $\mathrm{~ns}$ & $\mathrm{~ns}$ & $* *$ & $\mathrm{~ns}$ & $\mathrm{~ns}$ \\
\hline 4 & $\mathrm{~ns}$ & $\mathrm{~ns}$ & $\mathrm{~ns}$ & $*$ & $* *$ & $\mathrm{~ns}$ & $\mathrm{~ns}$ & ns & $* *$ & $\mathrm{~ns}$ & $\mathrm{~ns}$ \\
\hline 5 & $\mathrm{~ns}$ & $\mathrm{~ns}$ & $\mathrm{~ns}$ & ns & $* *$ & ns & $\mathrm{ns}$ & ns & $* *$ & $\mathrm{~ns}$ & $\mathrm{~ns}$ \\
\hline 6 & $* *$ & $* *$ & $\mathrm{~ns}$ & $\mathrm{~ns}$ & $\mathrm{~ns}$ & $\mathrm{~ns}$ & $\mathrm{~ns}$ & $\mathrm{~ns}$ & ns & $\mathrm{ns}$ & $\mathrm{ns}$ \\
\hline 7 & $*$ & $* *$ & $*$ & $\mathrm{~ns}$ & ns & $\mathrm{ns}$ & $\mathrm{ns}$ & $\mathrm{ns}$ & ns & $\mathrm{ns}$ & $\mathrm{ns}$ \\
\hline 8 & $\mathrm{~ns}$ & $\mathrm{~ns}$ & $\mathrm{~ns}$ & $*$ & $* *$ & $\mathrm{~ns}$ & $\mathrm{~ns}$ & $\mathrm{~ns}$ & $* *$ & $\mathrm{~ns}$ & $\mathrm{~ns}$ \\
\hline $\mathrm{R}^{2}$ & 0,51 & 0,64 & 0,49 & 0,79 & 0,49 & 0,42 & 0,02 & 0,31 & 0,46 & 0,28 & 0,40 \\
\hline $\mathrm{CV}$ & 14,47 & 31,72 & 0,84 & 10,26 & 9,28 & 7,33 & 5,74 & 12,79 & 9,15 & 9,60 & 9,69 \\
\hline Media & 39,40 & 20,29 & 38,10 & 7,83 & 14,34 & 15,66 & 35,23 & 9,21 & 40,75 & 44,59 & 6,41 \\
\hline
\end{tabular}

${ }^{* *} P<0,01$; ${ }^{*} P<0,05$, ns- não significativo, $C V$ - coeficiente de variação, $R^{2}$ - coeficiente de determinação, $X$ - média, $F C$ - freqüência cardíaca, FR - freqüência respiratória, TR - temperatura retal, LEUC - leucócitos $\left(\times 10^{3} / \mathrm{mm}^{3}\right), \mathrm{HEM}$ - hemácias $\left(\times 10^{6} / \mathrm{mm}^{3}\right), \mathrm{HEMO}$ - Hemoglobina (g/dl), VG(\%), VCM (fl), HCM (pg), CHCM (\%), PT- proteína plasmática total (g/dL). CONTRASTES: 1 - repouso versus exercício independente de horária, 2 - Manhã versus tarde em repouso 3 - baia versus sol à tarde, 4 - exercício (manhã versus tarde), 5- manhã versus tarde independente exercício, 6- exercício vs repouso de manhã, 7 - exercício versus repouso de tarde, 8 - baia versus sol de tarde

** $P<.01$; * $P<.05$, ns- not significant, CV - coefficient of variation, $R^{2}$ - coefficient of determination, $X$-mean. FC-heart bet, FR-breathing rate e TR-rectal temperature, LEUC-Leukocytes $\left(\times 10^{3} / \mathrm{mm}^{3}\right)$, HEM -Hemacias $-\left(\times 10^{6} / \mathrm{mm}^{3}\right)$, HEMO-Hemoglobin (g/dl), VG-globularvolume(\%), VCM-mean corpuscular volume (fl), HCM - mean corpuscular hemoglobin (pg), CHCM - concentration of mean corpuscular hemoglobin (\%), PROT- Total Protein (mg/dl); CONTRASTS: 1- rest versus exercise independent of time, 2 - morning versus afternoon at rest; 3- stall versus sun in afternoon; 4 - exercise (morning versus afternoon), 5- morning versus afternoon independent of exercise, 6- exercise versus rest afternoon, 7 - exercise versus rest afternoon, 8-stall versus sun afternoon.

ou exercício vigoroso (Coles, 1984; Jain, 1993). Contudo, o efeito é passageiro, persistindo por um pequeno intervalo de tempo, normalmente menor que 30 minutos (Lassen \& Swardson, 1995). No estudo, podemos observar uma diferença de adaptação ao estresse entre as raças, sendo que provavelmente, ocorreu uma maior liberação de corticosteróides nos BH e menor nos Bretões, o que poderia justificar uma menor adaptação dos primeiros. Como os $\mathrm{BH}$ e os mestiços apresentaram maior aumento no número de leucócitos após o exercício $(\mathrm{p}<0,01)$ podemos concluir que seus organismos sofreram maiores desgastes, respondendo com uma maior liberação de cortisol, o qual estimulou a migração de células de defesa para a circulação periférica na tentativa de adaptação à situação, concordando com Rose et al. (1983), Lassourd et al. (1996) e Nogueira \& Barnabe (1997).

A média dos valores hematológicos normais variou de acordo com a raça do animal e em qual categoria esta se encontra. Animais de "sangue quente" demonstraram maiores valores totais de hemácias, hemoglobina e VG, concordando com Lassen \& Swardson (1995). Exemplo de animais que se enquadraram no topo dessa categoria foram os PSC. Já os Bretões encontraram-se como os principais animais de "sangue frio" apresentando valores hematimétricos mais reduzidos. Os mestiços e os BH são animais em transição possuindo valores intermediários. Os mestiços aproximaram-se bem mais aos valores do PSC.

Segundo Jain (1993), os eqüinos "sangue quente" deveriam exceder de 2 a 3 milhões de eritrócitos/ $\mathrm{ml}$ às contagens do cavalo de "sangue frio". Tal afirmação pôde ser comprovada já que os Bretões possuíam valores de 6,6 milhões de eritrócitos $/ \mathrm{ml}$ enquanto que os PSC atingiram 8,5 milhões $/ \mathrm{ml}$ no descanso, sendo esta diferença condizente com aquela citada anteriormente. Conforme descrito por Coles (1984), os animais de "sangue-quente" possu- 
Tabela 5 - Análise de variância dos parâmetros fisiológicos dos cavalos do Exército Brasileiro Table 5 - Variance analysis for physiological parameters in horses in the Brazilian Army

\begin{tabular}{|c|c|c|c|c|c|c|c|c|}
\hline & $\mathrm{FC}$ & FR & TR & LEUC & $\mathrm{HB}$ & HEM & $\mathrm{VG}$ & PT \\
\hline $\begin{array}{l}\text { Conjunto } \\
\text { Group }\end{array}$ & $\mathrm{ns}$ & $\mathrm{ns}$ & $\mathrm{ns}$ & $\mathrm{ns}$ & $\mathrm{ns}$ & Ns & $\mathrm{ns}$ & $\mathrm{ns}$ \\
\hline $\begin{array}{l}\text { Animal dentro de grupo } \\
\text { Animal within group }\end{array}$ & $* *$ & $* *$ & $* *$ & $* *$ & $* *$ & $* *$ & $* *$ & $* *$ \\
\hline $\begin{array}{l}\text { Data } \\
\text { Date }\end{array}$ & $\mathrm{ns}$ & $* *$ & $* *$ & $\mathrm{~ns}$ & $\mathrm{~ns}$ & $* *$ & $*$ & $* *$ \\
\hline $\begin{array}{l}\text { Tratamento } \\
\text { Treatment }\end{array}$ & $* *$ & $* *$ & $* *$ & $*$ & $* *$ & $* *$ & $* *$ & $* *$ \\
\hline $\begin{array}{l}\text { Raça } \\
\text { Breed }\end{array}$ & $* *$ & $* *$ & $* *$ & $* *$ & $* *$ & $* *$ & $* *$ & $\mathrm{~ns}$ \\
\hline $\begin{array}{l}\text { Tratamento x Raça } \\
\text { Treatment } x \text { Breed }\end{array}$ & $* *$ & $* *$ & $* *$ & $\mathrm{~ns}$ & $*$ & Ns & $*$ & $\mathrm{~ns}$ \\
\hline
\end{tabular}

\begin{tabular}{|c|c|c|c|c|c|c|c|}
\hline \multicolumn{8}{|c|}{ Contrastes } \\
\hline 1 & $* *$ & $* *$ & $* *$ & & & & \\
\hline 2 & $\mathrm{~ns}$ & $* *$ & $\mathrm{~ns}$ & & & & \\
\hline 3 & $* *$ & $* *$ & $* *$ & & & & \\
\hline 4 & $\mathrm{~ns}$ & $* *$ & $*$ & & & & \\
\hline 5 & $\mathrm{~ns}$ & $* *$ & $*$ & & & & \\
\hline 6 & $* *$ & $* *$ & $* *$ & & & & \\
\hline 7 & $* *$ & $* *$ & $* *$ & & & & \\
\hline $\mathrm{X}$ & 40,68 & 22,99 & 37,85 & 0,26 & 0,68 & 0,43 & 0,34 \\
\hline $\mathrm{CV}$ & 14,13 & 35,31 & 0,79 & 22,49 & 9,56 & 15,11 & 9,97 \\
\hline $\mathrm{R}^{2}$ & 0,64 & 0,56 & 0,56 & 7,31 & 12,85 & 8,12 & 6,59 \\
\hline
\end{tabular}

${ }^{* *} P<0,01 ;{ }^{*} P<0,05$, ns - não-significativo, $C V$ - coeficiente de variação, $R^{2}$ - coeficiente de determinação, $X$ - média. $F C$ - freqüência cardíaca, FR - freqüência respiratória, TR - temperatura retal, LEUC - Leucócitos $\left(\times 10^{3} / \mathrm{mm}^{3}\right)$, HEM - Hemácias $\left(\times 10^{6} / \mathrm{mm}^{3}\right)$, HB - Hemoglobina ( $/ \mathrm{dL})$, VG(\%), PT - proteína plasmática total $(\mathrm{g} / \mathrm{dL})$. Contrastes: 1 - repouso versus exercício, independentemente de horário, 2 - manhã versus tarde em repouso 3 - baia versus sol a tarde, 4 - exercício (manhã versus tarde), 5 - manhã versus tarde, independentemente de exercício, 6 - exercício versus repouso de manhã, 7 - exercício versus repouso de tarde.

${ }^{*}{ }^{*} P<.01 ;{ }^{*} P<.05$, ns - not significant, $C V$ - coefficient of variation, $R^{2}$ - coefficient of determination, $X$-mean. FC - heart beat, FR - breathing rate, $T R$ - rectal temperature , LEUC - Leukocytes $\left(\times 10^{3} / \mathrm{mm}^{3}\right)$, HEM - Hemacias $\left(\times 10^{6} / \mathrm{mm}^{3}\right), \mathrm{HB}-$ Hemoglobin (g/dL), VG - globular volume(\%), PROT - total protein ( $\mathrm{mg} / \mathrm{dL}$ ); CONTRASTS: 1 - rest versus exercise independent of time, 2 - morning versus afternoon at rest; 3 - stall versus sun in afternoon; 4 - exercise (morning versus afternoon), 5- morning versus afternoon independent of exercise, 6 - exercise versus rest afternoon, 7 - exercise versus rest afternoon.

em eritrócitos de menor tamanho e conseqüentemente em maior número se comparados aos cavalos de "sangue-frio".

Em relação ao aumento de hemácias após o exercício, este foi inversamente proporcional ao valor absoluto normal, ou seja, quanto menores os dados médios normais, maiores foram às alterações proporcionais. Estas alterações estão associadas com maior liberação de hemácias pelo baço, com finalidade de adaptação às condições adversas como calor e exercício, haja visto o aumento da necessidade de oxigenação dos tecidos nestas ocasiões (Jain, 1993).

Os índices totais eritrocitários mais elevados foram alcançados pelos PSC que já possuíam um nível elevado em repouso, desta forma, o aumento foi proporcionalmente o mais baixo. Os mestiços atingiram níveis de hemácias logo abaixo daqueles do PSC, logo, seu aumento proporcional foi levemente superi- or, mas sem diferir estatisticamente destes. Os Bretões foram os animais com índices mais baixos tanto antes quanto após o exercício, mesmo tendo sido os que sofreram um maior aumento relativo ao normal. Os BH ficaram intermediários, mais semelhantes aos Bretões com um aumento elevado, mas um valor absoluto inferior ao dos mestiços. Os Bretões foram os únicos que não apresentaram aumento eritrocitário $(\mathrm{p}<0,05)$ relevante após a prática de exercícios. O maior aumento percentual de hemácias pelos BH e pelos Mestiços pode ter sido devido a menor adaptação destes ao exercício, numa tentativa de aumentar a capacidade aeróbica destes durante o estresse físico, capacitando-os a superar os déficits fisiológicos deixando-os mais aptos a prática de exercícios, quando comparados aos PSC, que também apresentaram as menores FC e FR (Coles, 1984, McClay, 1990 e Lassen \& Swardson, 1995). 
O VG variou de forma similar aos eritrócitos no que diz respeito às alterações por raças. Os $\mathrm{BH}$ e os Bretões não apresentaram diferença $(\mathrm{p}>0,05)$ entre si, porém foram distintos $(\mathrm{p}<0,05)$ dos mestiços e $\mathrm{PSC}$, os quais também foram semelhantes entre si. $\mathrm{O}$ aumento conseqüente ao exercício foi significativo como uma média global, mas o aumento foi proporcionalmente similar entre as raças, não apresentando diferença estatística. Possivelmente, a principal causa deste aumento no VG foi o aumento eritrocitário resultante da contração esplênica (Lassen \& Swardson, 1995).

$\mathrm{O}$ valor médio da hemoglobina foi diferente $(p<0,01)$ entre todas as raças, exceto entre os PSC e os mestiços que obtiveram níveis bem próximos entre si. O exercício teve importância no aumento médio de hemoglobina no sangue. Todas as raças, com exceção dos BH, obtiveram acréscimos significativos no teor de hemoglobina no sangue, acompanhando o aumento eritrocitário, sendo os mestiços e os PSC as raças que apresentaram os maiores valores. Este aumento da hemoglobina é condizente com o incremento de hemácias, uma vez que esta está contida no interior dos eritrócitos e são os responsáveis pelos transportes dos gases, principalmente o oxigênio garantindo aumento da oxigenação exigida pelos tecidos em tais condições.

O aumento da PT foi similar em todas as raças. Os mestiços apresentaram as mais elevadas PT, diferindo $(\mathrm{p}<0,01)$ dos PSC e $\mathrm{BH}$ e, foram os únicos que apresentaram um aumento $(\mathrm{p}<0,05)$ na sua concentração quando comparadas as amostras retiradas antes e após a exposição ao sol e ao exercício, denotando maior perda de água corporal, principalmente pela sudorese, principal forma de dissipação de calor no eqüino (Hodgson et al., 1994), e respiração, levando a uma leve desidratação, com redução do plasma e conseqüente aumento da sua quantidade. Nesse momento, tanto a concentração de albumina quanto à de globulina estão elevadas permanecendo a proporção de Albumina:Globulina (A:G) normal (Jain, 1993; Hargreaves et al., 1999). Isso ocorre na tentativa de manter a termorregulação e suportar o

Tabela 6 - Análise de variância dos parâmetros fisiológicos dos cavalos Bretão do Exército Brasileiro Table 6 - Variance analysis for physiological parameters in Breton horses in the Brazilian Army

\begin{tabular}{|c|c|c|c|c|c|c|c|c|c|c|c|}
\hline & $\mathrm{FC}$ & FR & $\mathrm{TR}$ & LEUC & $\mathrm{HB}$ & HCM & $\mathrm{CHCM}$ & HEM & VG & VCM & PT \\
\hline Idade & $\mathrm{ns}$ & $\mathrm{ns}$ & $\mathrm{ns}$ & $\mathrm{ns}$ & $* *$ & $* *$ & $\mathrm{~ns}$ & $* *$ & $\mathrm{~ns}$ & $\mathrm{~ns}$ & $*$ \\
\hline Cor & - & - & - & - & - & - & - & - & - & - & - \\
\hline Data & $\mathrm{ns}$ & $*$ & $\mathrm{~ns}$ & $\mathrm{~ns}$ & $\mathrm{~ns}$ & $\mathrm{~ns}$ & $\mathrm{~ns}$ & $\mathrm{~ns}$ & $\mathrm{~ns}$ & $\mathrm{~ns}$ & $\mathrm{~ns}$ \\
\hline Grp & $* *$ & $* *$ & $* *$ & $\mathrm{~ns}$ & $*$ & $\mathrm{~ns}$ & $\mathrm{~ns}$ & $\mathrm{~ns}$ & $\mathrm{~ns}$ & $\mathrm{~ns}$ & $\mathrm{~ns}$ \\
\hline Peso & $\mathrm{ns}$ & $\mathrm{ns}$ & $\mathrm{ns}$ & $\mathrm{ns}$ & $\mathrm{ns}$ & $\mathrm{ns}$ & $\mathrm{ns}$ & $\mathrm{ns}$ & $\mathrm{ns}$ & $\mathrm{ns}$ & $\mathrm{ns}$ \\
\hline \multicolumn{12}{|c|}{ Contrastes } \\
\hline \multicolumn{12}{|c|}{ Contrasts } \\
\hline 1 & $* *$ & $* *$ & $* *$ & $\mathrm{~ns}$ & $\mathrm{~ns}$ & $\mathrm{~ns}$ & $\mathrm{~ns}$ & $\mathrm{~ns}$ & $\mathrm{~ns}$ & $\mathrm{~ns}$ & $\mathrm{~ns}$ \\
\hline 2 & $\mathrm{~ns}$ & $\mathrm{~ns}$ & $\mathrm{~ns}$ & $*$ & $* *$ & $*$ & $\mathrm{~ns}$ & $\mathrm{~ns}$ & $\mathrm{~ns}$ & $\mathrm{~ns}$ & $\mathrm{~ns}$ \\
\hline 3 & $\mathrm{~ns}$ & $\mathrm{~ns}$ & $\mathrm{~ns}$ & $\mathrm{~ns}$ & $\mathrm{~ns}$ & $*$ & $\mathrm{~ns}$ & $\mathrm{~ns}$ & $\mathrm{~ns}$ & $\mathrm{~ns}$ & $\mathrm{~ns}$ \\
\hline 4 & $\mathrm{~ns}$ & $\mathrm{~ns}$ & $\mathrm{~ns}$ & $\mathrm{~ns}$ & $\mathrm{~ns}$ & $*$ & ns & $\mathrm{ns}$ & $\mathrm{ns}$ & $\mathrm{ns}$ & $\mathrm{ns}$ \\
\hline 5 & $*$ & $\mathrm{~ns}$ & $*$ & $\mathrm{~ns}$ & $\mathrm{~ns}$ & $\mathrm{~ns}$ & $\mathrm{~ns}$ & $\mathrm{~ns}$ & $\mathrm{~ns}$ & $\mathrm{~ns}$ & $\mathrm{~ns}$ \\
\hline 6 & $* *$ & $* *$ & $* *$ & $\mathrm{~ns}$ & $\mathrm{~ns}$ & $\mathrm{~ns}$ & $\mathrm{~ns}$ & $\mathrm{~ns}$ & $\mathrm{~ns}$ & $\mathrm{~ns}$ & $\mathrm{~ns}$ \\
\hline 7 & $* *$ & $* *$ & $* *$ & $\mathrm{~ns}$ & $*$ & $\mathrm{~ns}$ & $\mathrm{~ns}$ & $\mathrm{~ns}$ & $\mathrm{~ns}$ & $\mathrm{~ns}$ & $\mathrm{~ns}$ \\
\hline 8 & $\mathrm{~ns}$ & $\mathrm{~ns}$ & $\mathrm{~ns}$ & $\mathrm{~ns}$ & $\mathrm{~ns}$ & $*$ & $\mathrm{~ns}$ & $\mathrm{~ns}$ & $\mathrm{~ns}$ & $\mathrm{~ns}$ & $\mathrm{~ns}$ \\
\hline $\mathrm{R}^{2}$ & 0,60 & 0,64 & 0,67 & 0,82 & 0,60 & 0,77 & 0,24 & 0,57 & 0,40 & 0,51 & 0,55 \\
\hline $\mathrm{CV}$ & 18,41 & 20,64 & 0,59 & 9,94 & 7,96 & 6,25 & 13,83 & 17,49 & 12,20 & 13,34 & 9,15 \\
\hline Media & 37,80 & 26,27 & 37,83 & 6,67 & 11,13 & 16,01 & 35,63 & 7,13 & 31,60 & 45,36 & 6,56 \\
\hline
\end{tabular}

\footnotetext{
** $\mathrm{P}<0,01$; * $\mathrm{P}<0,05$, ns - não-significativo, $C V$ - coeficiente de variação, $\mathrm{R}^{2}$ - coeficiente de determinação, $X$ - média, $\mathrm{FC}$ - freqüência

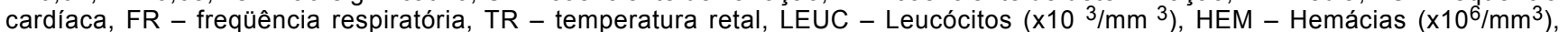
HB - Hemoglobina (g/dL), VG (\%), VCM (fl), HCM (pg), CHCM (\%), PT - proteína plasmática total (g/dL). Contrastes: 1 - repouso versus exercício, independentemente de horário, 2 - manhã versus tarde em repouso 3 - baia versus sol à tarde, 4 - exercício (manhã versus tarde), 5 - manhã versus tarde, independentemente de exercício, 6 - exercício versus repouso de manhã, 7 - exercício versus repouso de tarde.

${ }^{*} P<.01 ;{ }^{*} P<.05, n s-$ not significant, $C V$ - coefficient of variation, $R^{2}$ - coefficient of determination, $X-m e a n, F C-$ heart beat, FR - breathing rate, TR - rectal temperature, LEUC - leukocytes (x $\left.103 / \mathrm{mm}^{3}\right)$, HEM - Hemacias (x $\left.10 \% / \mathrm{mm}^{3}\right)$, HB - Hemoglobin (g/dL), VG - globular volume(\%), VCM - mean corpuscular volume (fI), HCM - mean corpuscular hemoglobin (pg), CHCM - concentration of mean corpuscular hemoglobin (\%), PROT-total protein ( $\mathrm{mg} / \mathrm{dL})$; CONTRASTS: 1 - rest versus exercise independent of time, 2 - morning versus afternoon at rest; 3 - stall versus sun in afternoon; 4 - exercise (morning versus afternoon), 5-morning versus afternoon independent of exercise, 6 - exercise versus rest afternoon, 7 - exercise versus rest afternoon.
}

R. Bras. Zootec., v.31, n.3, p.1130-1142, 2002 
exercício. Nos mestiços foi também observado, associado ao aumento de PT e devido ao volume plasmático reduzido, um aumento número de hemácias, no VG e na concentração de $\mathrm{Hb}$ (Coles, 1984).

Foi observado também o efeito da idade sobre a hematimetria normal dos eqüinos. As variações relacionadas à idade são constantes nos eqüinos. Uma análise do crescimento proporcional de hemácias após o exercício, classificando de acordo com faixa etária, mostrou que animais mais jovens (4 anos) e animais mais velhos (13 anos) foram os que obtiveram menores aumentos no número de eritrócitos, apesar de que o número total de hemácias ter sido mais alto para aqueles mais jovens. Aos 9 anos percebeu-se um elevado acréscimo de hemácias conseqüente da prática de exercícios, diferença tal que decresce, gradativamente, com aumento da idade até aos 13 anos.

Em relação aos leucócitos a quantidade média foi similar entre animais de 4 e de 13 anos e diferem significativamente às idades mais intermediárias. $\mathrm{O}$ valor de leucócitos decresce dos 4 aos 10 anos de idade significativamente, aos 11 anos começa a elevar-se progressivamente até os 13 anos. Estes dados indicam que os eqüinos situados nos extremos da faixa etária, principalmente os muito jovens, foram os mais estressados fisicamente, concordando com a afirmação de que a resposta leucocitária pelos corticóides pode variar conforme a idade (Coles,
1984). Segundo Jain (1993) e Lassen e Swardson (1995), os leucócitos são mais elevados para animais mais jovens reduzindo com o avançar da idade, o mesmo fato foi observado no experimento. Contudo, Jain (1993) cita animais de quatro anos possuindo valores leucocitários maiores que os com cinco anos, sendo o oposto do verificado no experimento.

A resposta do organismo também é diferente com o avançar da idade, podendo ser associada a uma redução da ação da atividade nervosa simpática e/ou das catecolaminas circulantes, resultando em níveis de contração esplênica diferenciada, frente a um mesmo estímulo estressante, determinando variações no número de hemácias. Além disso, a redução pode também estar associada ao fato de que os eritrócitos nos animais mais jovens serem maiores (Jain, 1993), o que faz com que se tenha menor quantidade de hemácias para que se possa ocupar um mesmo volume. O posterior aumento pode ser devido ao treinamento do eqüino, que leva ao aumento do número de hemácias e, conseqüentemente, de hemoglobina.

Apesar de Jain (1993) descrever que a idade aumenta a concentração de PT em muitas espécies, no presente estudo não houve diferença significativa desse parâmetro.

As correlações entre as características e peso estão na Tabela 7. As correlações entre peso e as outras características foram em geral baixas e negativas.

As correlações entre os parâmetros fisiológicos (FC, FR, TR) foram, em geral, de média a altas e

Tabela 7 - Correlações entre parâmetros fisiológicos e hematológicos em cavalos no DF

Table 7 - Correlations between physiological and hematological parameters in horses in the Federal District

\begin{tabular}{|c|c|c|c|c|c|c|c|c|c|c|c|c|}
\hline $\mathrm{X}$ & Peso & Idade & $\mathrm{FC}$ & FR & TR & LEUC & HEM & $\mathrm{HB}$ & $\mathrm{VG}$ & VCM & HCM & $\mathrm{CHCM}$ \\
\hline Idade & $-0,13$ & & & & & & & & & & & \\
\hline $\mathrm{FC}$ & $-0,06$ & 0,04 & & & & & & & & & & \\
\hline FR & 0,01 & 0,08 & 0,60 & & & & & & & & & \\
\hline $\mathrm{TR}$ & $-0,12$ & 0,10 & 0,46 & 0,53 & & & & & & & & \\
\hline LEUC & $-0,23$ & $-0,43$ & 0,17 & 0,30 & 0,22 & & & & & & & \\
\hline HEM & $-0,33$ & $-0,12$ & 0,14 & 0,22 & 0,32 & 0,35 & & & & & & \\
\hline $\mathrm{HB}$ & $-0,41$ & 0,13 & 0,28 & 0,23 & 0,44 & 0,31 & 0,64 & & & & & \\
\hline $\mathrm{VG}$ & $-0,38$ & 0,14 & 0,26 & 0,21 & 0,41 & 0,26 & 0,55 & 0,80 & & & & \\
\hline VCM & $-0,04$ & 0,27 & 0,11 & $-0,01$ & 0,09 & $-0,13$ & $-0,42$ & 0,15 & 0,50 & & & \\
\hline HCM & $-0,03$ & 0,31 & 0,14 & $-0,01$ & 0,07 & $-0,14$ & $-0,55$ & 0,30 & 0,18 & 0,70 & & \\
\hline CHCM & $-0,01$ & 0,08 & 0,02 & $-0,03$ & $-0,08$ & $-0,07$ & $-0,08$ & $-0,06$ & $-0,48$ & $-0,50$ & 0,04 & \\
\hline PT & $-0,05$ & 0,04 & 0,12 & 0,21 & 0,19 & 0,04 & 0,10 & 0,28 & 0,33 & 0,20 & 0,14 & $-0,11$ \\
\hline
\end{tabular}

FC - freqüência cardíaca, FR - freqüência respiratória, TR - temperatura retal, LEUC - leucócitos $\left(\mathrm{x} 10^{3} / \mathrm{mm}^{3}\right), \mathrm{HEM}-\mathrm{hemácias}\left(\times 10^{6} / \mathrm{mm}^{3}\right)$, HB - Hemoglobina (g/dL), VG(\%), VCM (fl), HCM (pg), CHCM (\%), PROT - proteína total (mg/dL), s - desvio-padrão, cv - coeficiente de variação, $\mathrm{BH}$ - brasileiro de hipismo, PSC - Puro Sangue de Corrida.

$F C$ - heart beat, FR - respiratory rate, TR - rectal temperature, LEUC - leukocytes ( $\left.\times 10^{3} / \mathrm{mm}^{3}\right)$, HEM - hemacias ( $\left.\times 10^{6} / \mathrm{mm}^{3}\right), \mathrm{HB}-\mathrm{Hemog} / \mathrm{obin}(\mathrm{g} / \mathrm{dL})$, VG (\%), VCM (fl), HCM (pg), CHCM (\%), PROT - total protein ( $\mathrm{mg} / \mathrm{dL}$ ), s - standard deviation, $\mathrm{cv}$ - coefficient of variation, BH - Brazilian showjumper, PSC-thoroughbred.

R. Bras. Zootec., v.31, n.3, p.1130-1142, 2002 
Tabela 8 - Componentes principais para parâmetros fisiológicos e hematológicos em cavalos no DF Table 8 - Principal components for physiological and hematological parameters in horses in the Federal District

\begin{tabular}{|c|c|c|c|c|c|c|c|}
\hline $\mathrm{X}$ & PRIN1 & PRIN2 & PRIN3 & PRIN4 & PRIN5 & PRIN6 & PRIN7 \\
\hline Peso & $-0,226$ & 0,050 & 0,309 & $-0,352$ & $-0,309$ & 0,141 & 0,699 \\
\hline Idade & 0,060 & 0,320 & 0,096 & 0,521 & $-0,354$ & $-0,223$ & $-0,195$ \\
\hline $\mathrm{FC}$ & 0,306 & $-0,039$ & 0,467 & $-0,047$ & 0,082 & $-0,142$ & $-0,002$ \\
\hline FR & 0,302 & $-0,110$ & 0,514 & $-0,113$ & $-0,104$ & $-0,066$ & $-0,217$ \\
\hline TR & 0,361 & $-0,043$ & 0,323 & 0,009 & $-0,154$ & $-0,117$ & 0,059 \\
\hline LEUC & 0,217 & $-0,293$ & $-0,022$ & $-0,306$ & 0,544 & 0,006 & $-0,132$ \\
\hline HEM & 0,302 & $-0,409$ & $-0,258$ & 0,149 & $-0,242$ & $-0,013$ & 0,208 \\
\hline $\mathrm{HB}$ & 0,438 & 0,009 & $-0,193$ & 0,250 & 0,133 & 0,118 & 0,408 \\
\hline $\mathrm{VG}$ & 0,451 & 0,122 & $-0,309$ & $-0,044$ & $-0,095$ & $-0,061$ & 0,165 \\
\hline VCM & 0,152 & 0,553 & $-0,081$ & $-0,251$ & 0,082 & $-0,115$ & $-0,043$ \\
\hline HCM & 0,094 & 0,517 & 0,119 & 0,103 & 0,427 & 0,113 & 0,221 \\
\hline CHCM & $-0,155$ & $-0,163$ & 0,298 & 0,573 & 0,335 & 0,271 & 0,172 \\
\hline PROT & 0,203 & 0,112 & 0,015 & $-0,081$ & $-0,234$ & 0,880 & $-0,296$ \\
\hline$\%$ & 0,277 & 0,191 & 0,128 & 0,104 & 0,080 & 0,069 & 0,050 \\
\hline
\end{tabular}

FC - freqüência cardíaca, FR - freqüência respiratória, TR - temperatura retal, LEUC - leucócitos $\left(\times 10^{3} / \mathrm{mm}^{3}\right), \mathrm{HEM}-$ hemácias $\left(\times 10^{6} / \mathrm{mm}^{3}\right)$, HB - Hemoglobina (g/dL), VG(\%), VCM (fl), HCM (pg), CHCM (\%), PROT - proteína total (mg/dL), s - desvio-padrão, cv - coeficiente de variação, BH - brasileiro de hipismo, PSC - Puro Sangue de Corrida.

$F C$ - heart beat, FR - respiratory rate, TR - rectal temperature, LEUC - leukocytes $\left(\times 10^{3} / \mathrm{mm}^{3}\right)$, HEM - Hemacias $\left(\times 10^{6} / \mathrm{mm}^{3}\right), \mathrm{HB}-\mathrm{Hemoglobin}(\mathrm{g} / \mathrm{dL})$, VG (\%), VCM (fl), HCM (pg), CHCM (\%), PROT - total protein (mg/dL), s - standard deviation, $c v$ - coefficient of variation, BH - Brazilian showjumper, PSC-thoroughbred.

Tabela 9 - Análise de variância dos parâmetros fisiológicos dos cavalos mestiços do Exército Brasileiro Table 9 - Variance analysis for physiological parameters in crossbred horses in the Brazilian Army

\begin{tabular}{|c|c|c|c|c|c|c|c|c|c|c|c|}
\hline & $\mathrm{FC}$ & FR & TR & LEUC & $\mathrm{HB}$ & $\mathrm{HCM}$ & $\mathrm{CHCM}$ & HEM & $\mathrm{VG}$ & VCM & PT \\
\hline Idade & $\mathrm{ns}$ & $\mathrm{ns}$ & $*$ & $\mathrm{~ns}$ & $\mathrm{~ns}$ & $\mathrm{~ns}$ & $\mathrm{~ns}$ & $\mathrm{~ns}$ & $\mathrm{~ns}$ & $\mathrm{~ns}$ & $\mathrm{~ns}$ \\
\hline Cor & $\mathrm{ns}$ & $*$ & $\mathrm{~ns}$ & $* *$ & $\mathrm{~ns}$ & $* *$ & $\mathrm{~ns}$ & $\mathrm{~ns}$ & $\mathrm{~ns}$ & $*$ & $\mathrm{~ns}$ \\
\hline Data & $*$ & $\mathrm{~ns}$ & $* *$ & $\mathrm{~ns}$ & $\mathrm{~ns}$ & $\mathrm{~ns}$ & $\mathrm{~ns}$ & $\mathrm{~ns}$ & $\mathrm{~ns}$ & $\mathrm{~ns}$ & ns \\
\hline Grp & $* *$ & $* *$ & $* *$ & $*$ & $* *$ & $\mathrm{~ns}$ & $\mathrm{~ns}$ & $\mathrm{~ns}$ & $* *$ & $*$ & $* *$ \\
\hline Peso & $\mathrm{ns}$ & $\mathrm{ns}$ & $\mathrm{ns}$ & $\mathrm{ns}$ & $\mathrm{ns}$ & $\mathrm{ns}$ & $\mathrm{ns}$ & $\mathrm{ns}$ & $\mathrm{ns}$ & $\mathrm{ns}$ & $\mathrm{ns}$ \\
\hline \multicolumn{12}{|c|}{ Contrastes } \\
\hline \multicolumn{12}{|c|}{ Contrasts } \\
\hline 1 & $* *$ & $*$ & $* *$ & $*$ & $* *$ & $*$ & $\mathrm{~ns}$ & $\mathrm{~ns}$ & $* *$ & $*$ & $* *$ \\
\hline 2 & $\mathrm{~ns}$ & $* *$ & $* *$ & $\mathrm{~ns}$ & $\mathrm{~ns}$ & $\mathrm{~ns}$ & $\mathrm{~ns}$ & $\mathrm{~ns}$ & $\mathrm{~ns}$ & $\mathrm{~ns}$ & $\mathrm{~ns}$ \\
\hline 3 & $* *$ & $* *$ & $* *$ & $\mathrm{~ns}$ & $\mathrm{~ns}$ & $\mathrm{~ns}$ & $\mathrm{~ns}$ & $\mathrm{~ns}$ & $\mathrm{~ns}$ & $\mathrm{~ns}$ & $\mathrm{~ns}$ \\
\hline 4 & $* *$ & $*$ & $* *$ & $\mathrm{~ns}$ & $\mathrm{~ns}$ & $\mathrm{~ns}$ & $\mathrm{~ns}$ & $\mathrm{~ns}$ & $\mathrm{~ns}$ & $\mathrm{~ns}$ & $\mathrm{~ns}$ \\
\hline 5 & $\mathrm{~ns}$ & $* *$ & $* *$ & $\mathrm{~ns}$ & $\mathrm{~ns}$ & $\mathrm{~ns}$ & $\mathrm{~ns}$ & $\mathrm{~ns}$ & $\mathrm{~ns}$ & $\mathrm{~ns}$ & $\mathrm{~ns}$ \\
\hline 6 & $* *$ & $*$ & $* *$ & $*$ & $* *$ & $*$ & $\mathrm{~ns}$ & $\mathrm{~ns}$ & $* *$ & $*$ & $\mathrm{~ns}$ \\
\hline 7 & $* *$ & $* *$ & $* *$ & $*$ & $* *$ & $\mathrm{~ns}$ & $\mathrm{~ns}$ & $\mathrm{~ns}$ & $* *$ & $\mathrm{~ns}$ & $* *$ \\
\hline 8 & $* *$ & $*$ & $* *$ & $\mathrm{~ns}$ & $\mathrm{~ns}$ & $\mathrm{~ns}$ & $\mathrm{~ns}$ & $\mathrm{~ns}$ & $\mathrm{~ns}$ & $\mathrm{~ns}$ & $\mathrm{~ns}$ \\
\hline $\mathrm{R}^{2}$ & 0,77 & 0,63 & 0,74 & 0,76 & 0,69 & 0,35 & 0,24 & 0,45 & 0,76 & 0,40 & 0,53 \\
\hline $\mathrm{CV}$ & 11,67 & 49,37 & 0,84 & 16,99 & 9,69 & 15,31 & 6,37 & 13,14 & 8,39 & 15,06 & 7,50 \\
\hline Média & 39,46 & 22,96 & 37,89 & 6,88 & 13,65 & 16,88 & 34,86 & 8,17 & 39,22 & 48,58 & 6,93 \\
\hline
\end{tabular}

${ }^{* *} \mathrm{P}<0,01$; * $\mathrm{P}<0,05$, ns - não-significativo, $C V$ - coeficiente de variação, $\mathrm{R}^{2}$ - coeficiente de determinação, $X$ - média, FC - freqüência cardíaca, FR - freqüência respiratória, TR - temperatura retal, LEUC - leucócitos $\left(\times 10^{3} / \mathrm{mm}^{3}\right)$, HEM - hemácias $\left(\times 10^{6} / \mathrm{mm}^{3}\right)$, HB - hemoglobina (g/dL), VG (\%), VCM (fl), HCM (pg), CHCM (\%), PT - proteína plasmática total (g/dL). Contrastes: 1 - repouso versus exercício, independentemente de horário, 2 - manhã versus tarde em repouso 3 - baia versus sol à tarde, 4 - exercício (manhã versus tarde), 5 - manhã versus tarde, independentemente de exercício, 6 - exercício versus repouso de manhã, 7 - exercício versus repouso de tarde.

${ }^{*}{ }^{*} P<.01 ;{ }^{*} P<.05$, ns - not significant, $C V$ - coefficient of variation, $R^{2}$ - coefficient of determination, $X-$ mean, FC - heart beat, FR - breathing rate, $T R$ - rectal temperature, LEUC - leukocytes $\left(\times 10^{3} / \mathrm{mm}^{3}\right)$, HEM - Hemacias (x $10^{6 / \mathrm{mm}^{3}}$ ), HB - Hemoglobin (g/dL), VG - globular volume $(\%)$, VCM - mean corpuscular volume (fl), HCM - mean corpuscular hemoglobin (pg), CHCM - concentration of mean corpuscular hemoglobin (\%), PROT-total protein (mg/dL); CONTRASTS: 1 - rest versus exercise independent of time, 2 - morning versus afternoon at rest; 3 - stall versus sun in afternoon; 4 - exercise (morning versus afternoon), 5 - morning versus afternoon independent of exercise, 6 - exercise versus rest afternoon, 7 - exercise versus rest afternoon. 
positivas (de 0,50 a 0,61 ), demonstrando que o aumento em um dos parâmetros (TR) em geral levava ao aumento no valor dos outros dois (FC e FR). O primeiro componente mostra que aumento em uma das características fisiológicas está acompanhado pelo aumento nas outras e o peso não está relacionado com estas características. No segundo componente, os parâmetros fisiológicos não são importantes, mas o peso é dominante. Estes primeiros dois componentes explicam $81,5 \%$ da variação existente entre as características. Em alguns animais (10,7\%) o aumento da TR não foi acompanhado de aumento na FC e FR (componente 3, não mostrado). Os componentes estão apresentados na Tabela 8 . Os primeiros dois componentes principais relacionados com estes dados estão na Figura 1.

$\mathrm{Na}$ análise de agrupamento, os animais foram divididos em três grupos: um deles composto pela raça Bretã e Mestiços, no qual as três variáveis aumentaram em conjunto, outro composto pela raça PSC no qual o aumento na TR foi acompanhado de pequeno aumento nos outros parâmetros e, outro

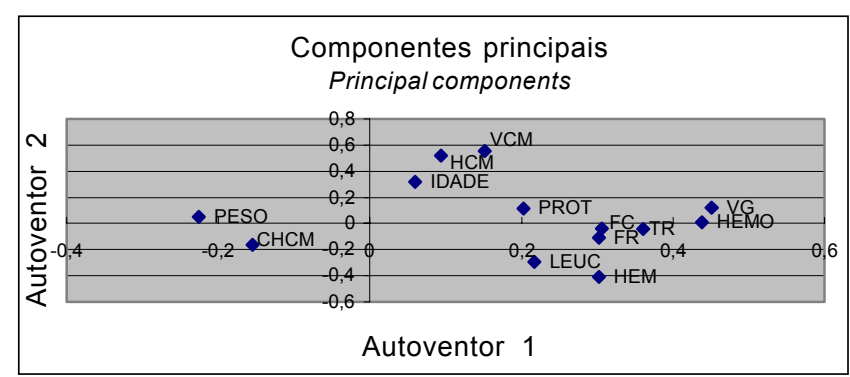

FC-freqüência cardíaca, FR - freqüência respiratória, TR - temperatura retal, LEUC - leucócitos $\left(x 10^{3} / \mathrm{mm}^{3}\right)$, HEM - Hemácias (x 10\%/mm $\left.{ }^{3}\right)$, HEMO - Hemoglobina $(\mathrm{g} / \mathrm{dL})$, VG(\%), VCM (fl), HCM (pg), CHCM (\%), PROT - proteína total (mg/dL), BH - brasileiro de hipismo, PSC - Puro Sangue de Corrida.

FC - heart beat, FR - respiratory rate, TR - rectal temperature, LEUC - leukocytes (x 103/ $\left.\mathrm{mm}^{3}\right)$, HEM - hemacias $\left(x 10^{6} / \mathrm{mm}^{3}\right)$, HEMO - hemoglobin (g/dL), VG(\%), VCM (fl), HCM (pg), CHCM (\%), $P R O T$ - total protein ( $\mathrm{mg} / \mathrm{dL}$ ).

Figura 1 - Componentes principais para parâmetros fisiológicas e de sangue em cavalos no DF.

Figure 1 - Principal components for fisiological and blood parameters in horses in the Federal District. composto pela raça $\mathrm{BH}$ no qual observou-se menor aumento na TR que nos outros grupos, acompanhado de aumento significativo dos outros parâmetros. As correlações na Tabela 7 são mais altas de que as achados por McManus et al. (1999) com gado mestiço de leite na mesma região.

Uma vez que a capacidade de se adaptar pode ser avaliada pela habilidade do animal se ajustar às condições ambientais médias, assim como aos extremos climáticos, com manutenção ou mínima perda no desempenho produtivo, esta adaptabilidade, no estudo realizado, ficou representada pela capacidade de ajustar a temperatura corpórea após o exercício e a exposição ao sol através de mecanismos de eliminação de calor. Dessa forma, animal com menor aumento na temperatura retal e menor freqüência respiratória é considerado mais tolerante ao calor (Baccari Jr., 1986).

\section{Conclusões}

Considerando as variações nos parâmetros fisiológicos, pode-se considerar que os animais $\mathrm{BH}$ e os Bretões foram os mais adaptados às condições de Brasília e os PSC e os Mestiços, os menos adaptados.

Quando considerado o perfil hematológico, observou-se que os PSC e os BH apresentaram as maiores leucometrias e eritrometrias, bem como os animais mais jovens e velhos, sendo, portanto, os menos adaptados.

Desse modo, de acordo com este experimento, pode-se concluir que a raça mais adequada para trabalho na região do Distrito Federal é a Bretã, devido à sua maior capacidade termorregulatória após exposição ao exercício e ao calor, resultando em um melhor desempenho produtivo e menor estresse para o animal.

\section{Literatura Citada}

BACCARI Jr., F. Métodos e técnicas de avaliação de adaptabilidade às condições tropicais In: SIMPÓSIO INTERNACIONAL DE BIOCLIMATOLOGIA ANIMAL NOS TRÓPICOS - PEQUENOS E GRANDES RUMINANTES, 1., 1986, Fortaleza. Anais... Fortaleza: 1986. p.9-17.

BARBOSA, O.R.; SILVA, R.G. Índice de conforto térmico para ovinos. Boletim de Indústria Animal, v.52, n.1, p.29-35, 1995.

BARRETT, M.A.; LARKIN, P.J. Producción lechera y de carne de res en los tropicos. México: Ed. Diana, 1979. 294p.

BOND, T.E. Solar atmospheric and terrestrial radiation received by shaded and unshaded animals. Trans ASAE, v.10, p.622-625, 1967.

R. Bras. Zootec., v.31, n.3, p.1130-1142, 2002 
BOUCHER, J.H.; FERGUSON, E.W.; WILHELMSEN, C.L. et al. Erytrocyte alterations during endurance exercise in horses. Journal of Applied Physiological, v.51, n.1, p.131-134, 1981.

BREWER, N.R. Exercise-induced pulmonary hemorrhage in horses. JAVMA, v.192, n.8, p.1012, 1988.

CHEUNG, S.S.; McLELLAN, T.M. Heat Acclimation, aerobic fitness, and hydration effects on tolerance during uncompensable heat stress. Journal of Applied Physiological, v.84, n.5, p.1731-1739, 1998.

COLES, E.H. Patologia clínica veterinária. Ed. Manole, 1984. 566p.

CRABBLE, B. Killler heat. Horse \& Rider, v.37, n.8, p.56-60, 1998.

CUNNINGHAM, J.G. Termorregulação. In: Tratado de fisiologia veterinária. São Paulo: Guanabara Koogan, 1999. p.507-514.

FOREMAN, J.H.; FERLAZZO, A. Physiological responses to stress in the horse. Pfrdeheilkunde, v.12, n.4, p.401-404 1996.

GUTHRIE, A.J.; LUND, R.J. Thermoregulation- Base mechanisms and hyperthermia. Vet Clinics of North American Equine Practice, v.14, n.1, p.45-59, 1998.

HARGRAVES, B.J.; KRONFELD, D.S.; NAYLOR, J.R.J. Ambient temperature and relative humidity influenced packed cell volume, total plasma protein and other variables in horses during an incremental submaximal field exercise test. Equine Veterinary Journal, v.31, n.4, p.314-318, 1999.

HODGSON, D.R.; DAVIS, R.E.; MCCONAUGHY, F.F. Thermoregulation in the horse in response to exercise. British Veterinary Journal, v.150, n.3, p.219-235, 1994.

JAIN, N.C. Essentials of veterinary hematology. Philadelphia: Lea \& Febiger, 1993. 417p.

JOLIFFE, I.T. Principal component analysis. New York: Springer-Verlag, 1986.265p.

KELLAWAY, R.C.; COLDITZ, P.J. The effect of heat stress on growth and nitrogen metabolism in Fresian and F1 brahman $\mathrm{x}$ fresian heifers. Australian Journal of Agriculture Research, v.26, p.615-622, 1975.

LASSEN, D.E.; SWARDSON, C.J. Hematology and hemostasis in the horse: normal functions and common abnormalities. Clin Pathol, v.11, n.3, p.351-389, 1995.
LASSOURD, V.; GAYRARD, V.; LAROUTE, V. et al. Cortisol disposition and production rate in horses during rest and exercise. The American Physiology Society, p.25-32, 1996.

MACKINNON, H.J.; MEYER, K.; HETZEL, D.J.S. Genetic variation and covariation for growth, parasite resistance and heat tolerance in tropical cattle. Livestock Production Science, v.27, n.2, p.105-122, 1991.

McCLAY, C.B.; WEISS, D.J.; SMITH,C.M. et al. Evaluation of hemorheologic vairables as implications for exercise induced pulmonary hemorrhage in facind thoroughbreds. Australian Jornal of Veterinay Research, v.53, n.8, p.1380-1385, 1992.

McMANUS, C.; BRENNER, H.; SAUERESSIG, M. Tolerância ao calor em vacas do sistema de dupla aptidão da embrapa cerrados. In: REUNIÃO ANUAL DA SOCIEDADE BRASILEIRA DE ZOOTECNIA, 1999, Porto Alegre. Anais... Porto Alegre: 1999 (CD ROM)

McMANUS, C.; MIRANDA, R.M.; Comparação das raças de ovinos Santa Inês e Bergamácia no Distrito Federal. Revista Brasileira de Zootecnia, v.26, n.5, p.627-636, 1997.

NOGUEIRA G.B.; BARNABE R.C.; Is the Throughbred racehorse under chronic stress? Brazilian Journal of Medical Biology Research, v.30, n.10, p.1237-1239, 1997.

ROSE, R.J.; ALLEN, J.R.; HODGSON, D.R. Responses to submaximal treadmill exercise and training in the horse: Changes in haematology, arterial blood gas and acid base measurements, plasma biochemical values and heart rate. The Veterinary Record, v.24, n.31, p.612-618, 1983.

SAS INSTITUTE. User's Guide. Version 8. Cary: 1999. 295p.

YOUSEF, M.K. Stress physiology in livestock. Boca Raton: CRC Press, 1985. 217p. 